Original article

\title{
Blood biochemical parameters in Yakut women with type 2 diabetes mellitus versus their somatotypes
}

\author{
Alla B. Guryeva, Vilyuia A. Alekseyeva \\ M.K. Ammosov North-Eastern Federal University
}

Received 21 April 2020, Revised 7 July 2020, Accepted 11 November 2020

(C) 2020, Guryeva A.B., Alekseyeva V.A.

(C) 2020, Russian Open Medical Journal

\begin{abstract}
Objective - Investigating the features of blood biochemical parameters in patients with type 2 diabetes mellitus (DM2), depending on the somatotype sensu the Rees-Eysenck body index.

Material and methods - We examined 88 women of Yakut nationality (39-74 years old) with an established diagnosis of DM2. An anthropometric examination with consequent somatotyping according to the Rees-Eysenck body index, along with determination of BMI were carried out. The biochemical blood test results were copied from the anamneses of female subjects. Statistical analysis was performed using the SPSS Statistics software package for Windows (version 17). Methods of parametric and nonparametric statistics were used.

Results - We established that the anthropometric parameters and BMI of women with DM2 were significantly higher. According to the BMI gradation, obesity was more common in people with DM2. The results of somatotyping implied that $11.4 \%, 50.0 \%$ and $38.6 \%$ of the examined women belonged to the asthenic, normosthenic and pyknic somatotypes, correspondingly. The distribution of somatotypes among women with DM2 differed from the general population distribution in a smaller fraction of individuals with asthenic somatotype. Blood biochemical parameters in subjects with asthenic body type were within the reference limits (except for glucose), in contrast to those of women with other somatotypes.

Conclusion - Women with asthenic somatotype are less at risk of developing DM2. Even if the ailment develops, their blood biochemical parameters remain within reference limits, with the exception of glucose.
\end{abstract}

Keywords: type 2 diabetes mellitus, women, somatotype, blood biochemical parameters, Yakutia.

Cite as Guryeva AB, Alekseyeva VA. Blood biochemical parameters in Yakut women with type 2 diabetes mellitus versus their somatotypes. Russian Open Medical Journal 2021; 10: e0208.

Correspondence to Alla B. Guryeva. Address: 34, Kulakovsky Street, Yakutsk, Russia. Phone: +79246638386. E-mail: guryevaab@mail.ru.

\section{Introduction}

In modern society, diabetes mellitus (DM) is the most acute problem in medicine due to the worldwide prevalence and annual increase in the number of patients. As of 2018, in the Republic of Sakha (Yakutia), the total number of DM patients was 24,266 people, of which 23,098 people were patients with type 2 diabetes mellitus (DM2) $[1,2]$. The enormous social and economic damage associated with high DM prevalence dictates the need for a comprehensive study of this issue. One of available methods for studying individual human health is the anthropological method. The somatotype of an individual can be a somatic sign of a predisposition to various ailments and an indicator of metabolic processes in the body [3].

A biochemical blood test is an informative diagnostic criterion for diagnosing, monitoring treatment and dynamics of the DM course. This method of laboratory diagnostics enables the judgement on the functions of internal organs, on metabolism quality, as well as on the content of trace elements.

Combining anthropological and biochemical research methods may help in making a diagnosis and in a better control and personalization of the disease course. The methodological substantiation of this approach can expand our views on the treatment of patients with DM.

Currently, the anthropometric aspect in DM2 issue is limited to analyzing some general patient-related information [4]. The somatotypological approach to this topic is not sufficiently disclosed in the scientific literature. Researchers point out the need to pay attention to somatotypes of DM patients rather than solely to the blood biochemical parameters [5]. In Yakutia, such studies were not carried out, which justifies the scientific novelty of our study.

Study goal: to reveal the peculiarities of the blood biochemical parameters in patients with type 2 diabetes mellitus, depending on their somatotypes sensu the Rees-Eysenck body index.

\section{Material and Methods}

A total of 88 women were examined with an established diagnosis of DM2, undergoing inpatient treatment at the endocrinology division of the Republican Hospital No. 2 'Emergency Medical Center'. The surveyed women were at this 
department from January through March 2019. Nationality was determined by survey method: all women were Yakut. The average age of women was 59.82 years (range 39-74 years). According to the age periodization, adopted by the USSR Academy of Pedagogical Sciences (1965), the surveyed women belonged to two age categories: the second stage of adulthood (from 36 to 55 years old) and senior age (56-74 years old).

The survey was conducted on a voluntary basis after obtaining written informed consent. Exclusion criteria were pregnancy, the presence of a pacemaker and cochlear implant, along with a refusal to be examined. The survey protocol was approved by the local ethics committee. The comparison group was represented by Yakut women (35-74 years old) without a diagnosis of DM2.

The first stage of our study involved an anthropometric examination. It was conducted in accordance with the classical method by V.V. Bunak [6]. Our measurements included body length and weight, waist and hip circumferences, and transverse chest diameter. The measurements were carried out using a height meter with an accuracy of $1 \mathrm{~mm}$, a medical balance with an accuracy of $100 \mathrm{~g}$, a tape meter with an accuracy of $1 \mathrm{~mm}$, and a thickness gauge with an accuracy of $5 \mathrm{~mm}$. The measurements were taken in the morning. The results were recorded in an individual anthropometric survey card.

Measured anthropometric indicators served the basis for an index assessment.

1. Somatotyping according to the Rees-Eysenck body index [7].

Rees-Eysenck body index = body height $(\mathrm{cm}) \times 100 /(T C D \times 6)$, where TCD is transverse chest diameter $(\mathrm{cm})$. Index values below 96.0 corresponds to the pyknic somatotype, 96 to 106 to normosthenic somatotype, and above 106 to asthenic somatotype. Somatotyping sensu Rees-Eysenck resulted in 10 asthenic female subjects $(11.4 \%$ of the sample size), 44 normosthenic women (55.0\%) and 34 females with a pyknic body type (38.6\%).

2. Body mass index (BMI) was computed as: $B M I=B M / B H^{2}$, where $B M$ is a body mass $(\mathrm{kg})$ and $B H$ is a body height $(\mathrm{m})$. The interpretation of BMI values was carried out as follows: under 18.5 $\mathrm{kg} / \mathrm{m}^{2}$ was regarded as underweight; from 18.5 to $24.9 \mathrm{~kg} / \mathrm{m}^{2}$ as normal body weight; from 25.0 to 30.0 as overweight; above 30.0 as obesity.

The second stage of our study included copying the results of biochemical blood tests from the medical histories of all examined women. Biochemical blood analyses were carried out at the biochemical laboratory of Yakutsk City Clinical Hospital. Blood samples were taken from subjects on an empty stomach from the cubital vein.

The third stage of our research involved statistical analysis using the SPSS Statistics software package for Windows (version 17) [8]. The median, along with lower and upper quartiles of values, Me (LQ-UQ), were computed. The significance of differences among the values of the indicators was assessed by the Mann-Whitney test. The significance of differences among relative indicators estimated via conducting the Pearson's Chi-squared test $\left(\chi^{2}\right)$. The value of $p<0.05$ implied statistically significant differences.

Table 1. Blood biochemical parameters in women with type 2 diabetes mellitus versus reference values

\begin{tabular}{lccc}
\hline Blood biochemical parameters & $M e$ & $(L Q-U Q)$ & Reference intervals \\
\hline Albumin, $\mathrm{g} / \mathrm{I}$ & 42.00 & $(39.00-43.60)$ & $37.0-52.0$ \\
Total protein, $\mathrm{g} / \mathrm{I}$ & 70.40 & $(65.30-72.98)$ & $64.0-83.0$ \\
Glucose, $\mathrm{mmol} / \mathrm{I}$ & 8.35 & $(5.55-10.91)$ & $3.8-6.3$ \\
Triglycerides, $\mathrm{mmol} / \mathrm{I}$ & 1.65 & $(1.33-2.08)$ & $0.4-1.8$ \\
Creatinine, $\mu \mathrm{mol} / \mathrm{I}$ & 73.50 & $(63.00-79.00)$ & $55.0-95.0$ \\
Urea, $\mathrm{mmol} / \mathrm{I}$ & 4.80 & $(4.40-6.50)$ & $2.8-7.2$ \\
Total cholesterol, $\mathrm{mmol} / \mathrm{I}$ & 4.80 & $(4.50-5.78)$ & $3.5-5.5$ \\
LDL cholesterol, $\mathrm{mmol} / \mathrm{l}$ & 3.00 & $(2.00-3.00)$ & $1.92-4.51$ \\
HDL cholesterol, $\mathrm{mmol} / \mathrm{I}$ & 1.20 & $(1.10-1.40)$ & $1.7-3.5$ \\
Total bilirubin, $\mu \mathrm{mol} / \mathrm{l}$ & 9.00 & $(7.25-13.00)$ & $8.5-20.5$ \\
Direct bilirubin, $\mu \mathrm{mol} / \mathrm{I}$ & 3.15 & $(2.33-4.00)$ & $1.0-20.0$ \\
ALT, IU/I & 23.30 & $(17.70-51.20)$ & $<35.0$ \\
AST, IU/I & 18.30 & $(15.70-38.50)$ & $<31.0$ \\
Calcium, mmol// & 2.30 & $(2.20-2.40)$ & $2.15-2.5$ \\
Magnesium, $\mathrm{mmol} / \mathrm{I}$ & 0.80 & $(0.70-0.90)$ & $0.65-1.0$ \\
Sodium, mmol/l & 138.00 & $(137.00-141.00)$ & $130.0-155.0$ \\
Potassium, $\mathrm{mmol} / \mathrm{I}$ & 4.20 & $(4.00-4.40)$ & $3.35-5.35$ \\
\hline
\end{tabular}

Table 2. Blood biochemical parameters in women with type 2 diabetes mellitus versus Rees-Eysenck body index

\begin{tabular}{|c|c|c|c|c|}
\hline Blood biochemical parameters & $\begin{array}{c}\text { Asthenic type } \\
(n=10) \text { Me (LQ-UQ) }\end{array}$ & $\begin{array}{l}\text { Normosthenic type } \\
(n=44) \text { Me (LQ-UQ) }\end{array}$ & $\begin{array}{c}\text { Pyknic type } \\
(n=34) M e(L Q-U Q)\end{array}$ & Statistical significance of difference, $p^{*}$ \\
\hline Albumin, g/l & $41.00(39.00-43.00)$ & $40.00(39.00-44.00)$ & 42.95 (39.00-43.80) & $\mathrm{p}_{1-2}=0.932 \mathrm{p}_{1-3}=0.523 \mathrm{p}_{2-3}=0.851$ \\
\hline Total protein, g/l & $69.80(67.60-72.60)$ & $71.30(65.20-75.80)$ & $69.30(65.00-72.60)$ & $p_{1-2}=0.671 p_{1-3}=0.586 p_{2-3}=0.366$ \\
\hline Glucose, mmol/l & $8.23(4.30-11.22)$ & 8.59 (6.14-14.15) & $7.91(5.03-9.96)$ & $\mathrm{p}_{1-2}=0.269 \mathrm{p}_{1-3}=0.928 \mathrm{p}_{2-3}=0.112$ \\
\hline Triglycerides, mmol/l & $1.60(1.50-1.70)$ & $1.70(1.20-2.00)$ & $1.60(1.40-2.20)$ & $p_{1-2}=0.550 p_{1-3}=1.000 p_{2-3}=0.595$ \\
\hline Creatinine, $\mu \mathrm{mol} / \mathrm{l}$ & $71.00(70.00-8.00)$ & $74.00(63.00-79.00)$ & $74.50(60.00-93.00)$ & $\mathrm{p}_{1-2}=0.733 \mathrm{p}_{1-3}=0.856 \mathrm{p}_{2-3}=0.876$ \\
\hline Urea, $\mathrm{mmol} / \mathrm{l}$ & $4.40(3.80-4.40)$ & $6.40(4.50-8.00)$ & $4.50(4.35-5.60)$ & $\mathrm{p}_{1-2}=0.017 \mathrm{p}_{1-3}=0.021 \mathrm{p}_{2-3}=0.075$ \\
\hline Total cholesterol, mmol/l & $4.60(4.30-5.80)$ & $4.90(4.50-5.40)$ & $5.00(4.50-5.80)$ & $p_{1-2}=0.551 p_{1-3}=0.650 p_{2-3}=0.708$ \\
\hline LDL cholesterol, mmol/l & $2.00(2.00-3.00)$ & $3.00(2.00-3.00)$ & $2.85(2.00-3.80)$ & $\mathrm{p}_{1-2}=0.110 \mathrm{p}_{1-3}=0.211 \mathrm{p}_{2-3}=0.843$ \\
\hline HDL cholesterol, mmol/l & $1.50(1.00-1.50)$ & $1.20(1.10-1.30)$ & $1.15(0.90-1.40)$ & $p_{1-2}=0.224 p_{1-3}=0.201 p_{2-3}=0.659$ \\
\hline Total bilirubin, $\mu \mathrm{mol} / \mathrm{l}$ & $11.00(9.00-12.00)$ & $11.00(8.00-13.00)$ & $8.00(5.00-9.00)$ & $\mathrm{p}_{1-2}=0.864 \mathrm{p}_{1-3}=0.056 \mathrm{p}_{2-3}=0.017$ \\
\hline Direct bilirubin, $\mu \mathrm{mol} / \mathrm{l}$ & $3.90(2.60-4.50)$ & $3.40(2.60-4.30)$ & $2.50(2.20-3.50)$ & $p_{1-2}=0.734 p_{1-3}=0.033 p_{2-3}=0.003$ \\
\hline$A L T, I U / I$ & $22.40(13.00-1.20)$ & $24.50(23.00-68.40)$ & $22.30(16.05-35.45)$ & $\mathrm{p}_{1-2}=0.148 \mathrm{p}_{1-3}=0.847 \mathrm{p}_{2-3}=0.004$ \\
\hline AST, IU/I & $16.80(15.70-5.20)$ & $19.40(18.10-43.10)$ & $17.90(13.75-27.28)$ & $\mathrm{p}_{1-2}=0.269 \mathrm{p}_{1-3}=1.000 \mathrm{p}_{2-3}=0.026$ \\
\hline Calcium, mmol/l & $2.40(2.30-2.50)$ & $2.30(2.20-2.30)$ & $2.20(2.20-2.43)$ & $p_{1-2}=0.008 p_{1-3}=0.070 p_{2-3}=0.334$ \\
\hline Magnesium, mmol/l & $0.90(0.80-0.90)$ & $0.80(0.70-0.80)$ & $0.80(0.80-0.90)$ & $\mathrm{p}_{1-2}=0.035 \mathrm{p}_{1-3}=0.041 \mathrm{p}_{2-3}=0.324$ \\
\hline Sodium, mmol/l & $138.00(137.00-41.00)$ & $139.00(137.00-141.00)$ & $138.00(135.00-141.00)$ & $\mathrm{p}_{1-2}=1.000 \mathrm{p}_{1-3}=0.709 \mathrm{p}_{2-3}=0.555$ \\
\hline Potassium, mmol/l & $4.00(3.90-4.20)$ & $4.15(4.00-4.40)$ & $4.30(4.00-4.40)$ & $p_{1-2}=0.233 p_{1-3}=.026 p_{1-3}=0.042 p_{2-3}=0.176$ \\
\hline
\end{tabular}

\footnotetext{
* $-p$-values from the Mann-Whitney test
} 


\section{Results}

Anthropometric examination included measurement of body height and weight, transverse chest diameter, and waist and hip circumferences. The body height in women was $157.0 \mathrm{~cm}(153.00-$ 161.25), body weight was $75.00 \mathrm{~kg}$ (69.50-86.75), waist circumference averaged $95.00 \mathrm{~cm}$ (89.00-103.25), and hip circumference was measured at $103.00 \mathrm{~cm}$ (95.00-108.50). The transverse chest diameter was $27.00 \mathrm{~cm}$ (26.00-29.00).

Anthropometric indicators of women with DM2 were compared with those of women of the Yakut nationality of the same age without the DM diagnosis. In women without DM, body weight was $61.25 \mathrm{~kg}$ (55.20-70.50), waist circumference averaged $90.18 \mathrm{~cm}$ (82.67-94.14), hip circumference was measured at $100.20 \mathrm{~cm}$ (91.85-104.60), while the transverse chest diameter was $25.00 \mathrm{~cm}$ (24.20-27.48) [9]. It was established that these parameters were significantly higher in women with DM2 $(p<0.001)$.

Based on the overall body size values, the BMI of women was calculated, and comparisons among the indicators of women with and without DM2 were conducted. The median BMI of women with DM2 was $30.90 \mathrm{~kg} / \mathrm{m}^{2}$ (27.62-33.40), which was significantly higher $(p<0.001)$ than BMI of women without DM2 $\left(26.62 \mathrm{~kg} / \mathrm{m}^{2}\right.$ (22.93-29.43)). According to the BMI value among DM2 women, persons with a body weight deficit (BMI under $18.5 \mathrm{~kg} / \mathrm{m}^{2}$ ) were not identified. Normal body weight was found in $9.1 \%$ of the surveyed women, while overweight women constituted $31.8 \%$ and obese females represented $59.1 \%$ of all studied women. Analysis of the distribution of BMI variants in women of two groups (with and without $\mathrm{DM} 2$ ) revealed that obesity was significantly more frequent in subjects with diabetes. In the group of people without DM2, the proportion of obese women was $20.1 \%(p<0.001$; $\chi^{2}=25.688$; the critical value of $\chi^{2}$ at a significance level of $p=0.01$ is 6.635).

The biochemical parameters in the blood of women with an established diagnosis of DM2 were identified (Table 1). Comparison of the average values of blood biochemical parameters with generally accepted reference intervals revealed that, in women with DM2, such parameters, as glucose, triglycerides, and ALT were elevated. Low HDL values in DM2 women were established.

Biochemical blood parameters in women with DM2, depending on the somatotype, according to the Rees-Eysenck body index, are presented in Table 2. It was revealed that the level of triglycerides $(1.95 \mathrm{mmol} / \mathrm{l})$ was increased in individuals of the pyknic somatotype, while in persons with asthenic and normosthenic somatotypes, this indicator was within the normal range of values. We discovered that in women with normosthenic and pyknic somatotypes, the levels of urea and ALT were significantly higher than in women with asthenic body type. In the latter, these blood parameters were within the normal range. The content of direct bilirubin was significantly higher in women with normosthenic somatotype.

\section{Discussion}

Anthropometric indicators (body weight, waist and hip circumferences, transverse chest diameter) of women with DM2 were significantly higher than those of Yakut women of the same age without the DM diagnosis. In terms of BMI, obesity was significantly more frequent in individuals with DM, than in women without it (59.1\% vs. $20.1 \%)$. Among DM2 women, underweight individuals were not identified, which significantly differed from the comparison group [10]. Among women without DM, underweight individuals occurred in $2.8 \%$ of cases. Such distribution of BMI corresponds to the characteristics of people with DM2 [11, 12].

In women with DM2, the values of such blood biochemical parameters, as glucose, triglycerides, and ALT, were elevated. Low HDL values were detected in women with DM2. Similar data regarding listed biochemical parameters of blood in Yakut nationals with DM2 was observed by other researchers as well [13]. Hence, listed biochemical parameters of blood are important diagnostic criteria in conditions of diabetes mellitus.

Analyzing distribution of somatotypes, according to the ReesEysenck body index, we discovered that in the surveyed group, the majority of women belonged to normosthenic and pyknic somatotypes. A statistically significantly smaller proportion of people had asthenic body type $\left(\chi^{2}=16.867 ; p<0.001\right)$. The resulting distribution of somatotypes among women with DM2 significantly differed from the general population distribution in a smaller percentage of people with asthenic somatotype. This finding could be interpreted as a lower susceptibility of individuals with asthenic somatotype to DM2.

The dependence of blood biochemical parameters in women of Yakut nationality with DM2 on their somatotypes sensu the Rees-Eysenck body index was revealed. It was determined that in persons with asthenic body type, the biochemical blood parameters were within the established reference intervals (except for the glucose level). In women with normosthenic and pyknic somatotypes, we discovered disorders of several blood biochemical parameters.

\section{Conclusion}

The results of our study revealed that the distribution of somatotypes, according to the Rees-Eysenck body index among Yakut women with DM2 significantly differed from the general population distribution in a smaller fraction of individuals with asthenic somatotype. Most women belonged to the normosthenic and pyknic somatotypes. The dependence of the blood biochemical parameters in DM2 women on the somatotype, according to the Rees-Eysenck index, was established. The biochemical parameters of blood in women with asthenic body type were within the established reference intervals (with the exception of glucose levels), in contrast to the women with other somatotypes. According to the results of the study, it can be argued that women with an asthenic body type are less at risk of developing type 2 diabetes mellitus and, in the case of the development of the disease, blood biochemical parameters remain within the normal range, with the exception of glucose. The conducted research allowed us to supplement the characteristics of the diabetes mellitus course with new information.

\section{Ethical approval}

All procedures in our study involving human participants were performed in accordance with the ethical standards of the institutional and/or national research committee, as well as with the 1964 Declaration of Helsinki and its later amendments or comparable ethical standards.

\section{Conflict of Interest}

The authors declare no conflicts of interest. 


\section{References}

1. Dedov II, Shestakova MV, Vikulova OK, Isakov MA, Zheleznyakova AV. Atlas of the diabetes registry in the Russian Federation, Status 2018. Diabetes Mellitus 2019; 22(S2-2): 4-61. Russian. https://www.elibrary.ru/item.asp?id=41436743.

2. Sydykova LA. Analysis of antidiabetic drug therapy of patients with diabetes mellitus in the republic of sakha (Yakutia). Vestnik of NorthEastern Federal University. Series: Medical Sciences. 2016; (3 (04)): 9698. Russian. https://www.elibrary.ru/item.asp?id=27330050.

3. Nikolaev VG, Medvedeva NN, Nikolenko VN, Petrova MM, Sindeyeva LV, Nikolaeva NN, et al. Essays in Integrative Anthropology. Krasnoyarsk: KrasGMU. 2015; 317 p. Russian. https://www.elibrary.ru/item.asp?id=25602405.

4. Dedov II, Shestakova MV, Vikulova OK, Zheleznyakova AV, Isakov MA, Serkov AA. Dynamics of the major epidemiological characteristics of diabetes mellitus in the Russian Federation in 2014-2018. In: Personalized Medicine and Practical Healthcare: Proceedings of the VIII (XXVI) National Endocrinology Congress with international participation. Moscow: UP Print. 2019: 65-66. Russian. https://www.elibrary.ru/item.asp?id=41430444.

5. Shchuplova IS, Bets LV. Anthropological approaches to the investigation of the problem of daibetes mellitus. Moscow University Anthropology Bulletin. 2014; (2): 56-64. Russian. https://www.elibrary.ru/item.asp?id=21653147.

6. Bunak V.V. Anthropometry. Moscow: Narkompros RSFSR. 1941; 368 p. Russian.

7. Rees ZA, Eisenk H. A factorial study of some morphological aspects of human constitution. J Mental Sci 1945; 91: 219-232.

8. Glants S. Medical and Biological Statistics. Moscow: Praktika. 1998; 321 p. Russian. https://www.booksmed.com/zdravooxranenie/1525mediko-biologicheskaya-statistika-glanc.html.

9. Guryeva A.B. Specificities of the anatomical structure variability in women of the Republic of Sakha (Yakutia). DSc Dissertation. Krasnoyarsk, 2019; 245 p. Russian.

10. Gureva AB, Nikolaev VG, Alekseeva VA. Ethno-age features of the physical status of the female population of the Republic of Sakha (Yakutia). Modern problems of science and education 2018; (4): 181. Russian. https://www.elibrary.ru/item.asp?id=36344997.

11. Barrett $M$, McClure R, Villani A. Adiposity is inversely associated with strength in older adults with type 2 diabetes mellitus. Eur Geriatr Med 2020; 11(3): 451-458. https://doi.org/10.1007/s41999-020-00309-y.

12. Dzhavahishvili TSh, Romancova TI, Roik OV. Body mass dynamics in patients with type 2 diabetes mellitus during the first year of insulin therapy. Obesity and Metabolism 2010; 7(4): 13-19. Russian. https://www.elibrary.ru/item.asp?id=15502727.

13. Kuzmina SS, Soloveva MI. Features of blood biochemical parameters changes in patients with type 2 diabetes mellitus in Yakutsk. Vestnik of North-Eastern Federal University 2017; No. (4 (60)): 13-22. Russian. https://www.elibrary.ru/item.asp?id=29876168.

Authors:

Alla B. Guryeva - DSc, Professor, Department of Normal and Pathological Anatomy, Operative Surgery with Topographic Anatomy and Forensic Medicine, Medical Institute, M.K. Ammosov North-Eastern Federal University, Yakutsk, Russia. https://orcid.org/0000-0003-2398-0542.

Vilyuia A. Alekseyeva - PhD, Associate Professor, Department of Normal and Pathological Human Physiology, Medical Institute, M.K. Ammosov North-Eastern Federal University, Yakutsk, Russia. https://orcid.org/00000002-9425-3062. 